Methodology article

Open Access

\title{
Innovative approach for transcriptomic analysis of obligate intracellular pathogen: selective capture of transcribed sequences of Ehrlichia ruminantium
}

Loïc Emboulé*1, France Daigle ${ }^{2}$, Damien F Meyer ${ }^{1}$, Bernard Mari3, Valérie Pinarello ${ }^{1}$, Christian Sheikboudou ${ }^{1}$, Virginie Magnone ${ }^{3}$, Roger Frutos ${ }^{4}$, Alain Viari ${ }^{5}$, Pascal Barbry ${ }^{3}$, Dominique Martinez ${ }^{4}$, Thierry Lefrançois ${ }^{1}$ and Nathalie Vachiéry* ${ }^{1}$

Address: ${ }^{1}$ UMR 15 CIRAD-INRA «Contrôle des maladies animales exotiques et émergentes», Site de Duclos, Prise d'Eau 97170, Petit Bourg, Guadeloupe, ${ }^{2}$ Département de microbiologie et immunologie, Université de Montréal, C.P 6128 succursale Centre-ville, Montréal, QC H3C3J7, Canada, ${ }^{3}$ UMR6097, CNRS-Université de Nice Sophia Antipolis, Institut de Pharmacologie Moléculaire et cellulaire, Sophia Antipolis, F06560, France, ${ }^{4}$ UMR 15 CIRAD-INRA «Contrôle des maladies animales exotiques et émergentes», TA 30/G Campus international de Baillarguet 34398 Montpellier Cedex 5, France and 'Inria Rhône-Alpes Projet HELIX, 655 Av. de l'Europe, 38330 Montbonnot-Saint Martin, France

Email: Loïc Emboulé* - loic.emboule@cirad.fr; France Daigle - france.daigle@umontreal.ca; Damien F Meyer - damien.meyer@cirad.fr; Bernard Mari - bernard.mari@unice.fr; Valérie Pinarello - valerie.pinarello@cirad.fr; Christian Sheikboudou - christian.sheikboudou@cirad.fr; Virginie Magnone - magnone@ipmc.cnrs.fr; Roger Frutos - roger.frutos@cirad.fr; Alain Viari - Alain.Viari@inrialpes.fr;

Pascal Barbry - barbry@ipmc.cnrs.fr; Dominique Martinez - dominique.martinez@cirad.fr; Thierry Lefrançois - thierry.lefrancois@cirad.fr; Nathalie Vachiéry* - nathalie.vachiery@cirad.fr

* Corresponding authors

Published: 24 December 2009

BMC Molecular Biology 2009, 10:11I doi:10.1186/147I-2199-10-III
Received: 9 April 2009

Accepted: 24 December 2009

This article is available from: http://www.biomedcentral.com/I47I-2/99/I0/III

(C) 2009 Emboulé et al; licensee BioMed Central Ltd.

This is an Open Access article distributed under the terms of the Creative Commons Attribution License (http://creativecommons.org/licenses/by/2.0), which permits unrestricted use, distribution, and reproduction in any medium, provided the original work is properly cited.

\begin{abstract}
Background: Whole genome transcriptomic analysis is a powerful approach to elucidate the molecular mechanisms controlling the pathogenesis of obligate intracellular bacteria. However, the major hurdle resides in the low quantity of prokaryotic mRNAs extracted from host cells. Our model Ehrlichia ruminantium (ER), the causative agent of heartwater, is transmitted by tick Amblyomma variegatum. This bacterium affects wild and domestic ruminants and is present in SubSaharan Africa and the Caribbean islands. Because of its strictly intracellular location, which constitutes a limitation for its extensive study, the molecular mechanisms involved in its pathogenicity are still poorly understood.

Results: We successfully adapted the SCOTS method (Selective Capture of Transcribed Sequences) on the model Rickettsiales ER to capture mRNAs. Southern Blots and RT-PCR revealed an enrichment of ER's CDNAs and a diminution of ribosomal contaminants after three rounds of capture. QRT-PCR and whole-genome ER microarrays hybridizations demonstrated that SCOTS method introduced only a limited bias on gene expression. Indeed, we confirmed the differential gene expression between poorly and highly expressed genes before and after SCOTS captures. The comparative gene expression obtained from $E R$ microarrays data, on samples before and after SCOTS at 96 hpi was significantly correlated $\left(R^{2}=0.7\right)$. Moreover, SCOTS method is crucial for microarrays analysis of $E R$, especially for early time points post-infection. There was low detection of transcripts for untreated samples whereas $24 \%$ and $70.7 \%$ were revealed for SCOTS samples at 24 and 96 hpi respectively.
\end{abstract}




\begin{abstract}
Conclusions: We conclude that this SCOTS method has a key importance for the transcriptomic analysis of $E R$ and can be potentially used for other Rickettsiales. This study constitutes the first step for further gene expression analyses that will lead to a better understanding of both $E R$ pathogenicity and the adaptation of obligate intracellular bacteria to their environment.
\end{abstract}

\section{Background}

Elucidating molecular mechanisms that drive the adaptation of obligate intracellular pathogens to their host is crucial to understand their pathogenesis. To date, molecular studies on obligate intracellular bacteria can only be performed ex vivo at one time or in vitro in host cells. Thus, RNA extraction from infected cell cultures leads to low quantities of prokaryotic mRNAs with short half-lives and a high amount of contaminant eukaryotic RNAs $[1,2]$. Moreover, in prokaryotic RNA, ribosomal RNAs (rRNAs) represent more than $80 \%$ of total RNA, whereas mRNAs represent only $2 \%$ of total RNAs. Therefore, high throughput gene expression analysis of obligate intracellular bacteria depends strongly on the quality of mRNAs samples, deprived from ribosomal RNAs and host RNAs. Up to recently, no methods were available to obtain purified obligate intracellular bacteria mRNAs from infected cells. Various methods can be used to monitor the complete set of RNA molecules produced by a microorganism, including both targeted and random approaches. Among the latter are differential expression of customized amplification libraries (DECAL) [3] and Selective Capture Of Transcribed Sequences (SCOTS) [4], techniques that combine polymerase chain reaction (PCR) and subtractive hybridization in order to identify genes that are expressed differentially. DECAL method is a powerful technique that permits global comparisons of bacterial gene expression under various growth conditions. It allows direct determination of differential gene expression by comparison of relative intensity with which PCR probes hybridize with individual colonies. However, this method has the disadvantage of being time-consuming and more complex to implement because of the construction of the Customized Amplification Library (CAL). Moreover, this technique does not assure to cover all the genome and several genes could be not detected, thus compelling to construct more complete CALs. Selective capture of transcribed sequences (SCOTS) was initially developed by Graham and ClarkCurtiss in 1999 for the non obligatory intracellular pathogen Mycobacterium tuberculosis and allowed to enlighten bacterial gene expression from different growth conditions in macrophages cells. It was also later used for Salmonella enterica serovar Typhi [5] and then used successfully for further transcriptomic microarray analysis [6]. Recently, SCOTS was employed to identify the in vivo expression of several genes of Actinobacillus pleuropneumoniae at different developmental stages post infection $[7,8]$ but was never applied on obligate intracellular pathogens.
The Rickettsia Ehrlichia ruminantium (ER), (previously Cowdria ruminantium) is the causative agent of heartwater, which affects both wild and domestic ruminants and is transmitted by ticks of the genus Amblyomma [9]. Heartwater represents a serious problem for livestock productivity in endemic areas such as sub-Saharan Africa and the West-indies and it poses a severe threat to livestock in the American continent due to migratory birds and the presence of potential indigenous vector ticks $[10,11]$. The genotypic heterogeneity of the bacterium leads to difficulties for the generation of an efficient vaccine [12-15]. Little is known about the genetic determinants and molecular mechanisms of ER pathogenesis, due to its isolated intracellular location. ER was considered to be a good model to evaluate the feasibility of SCOTS method for obligate intracellular bacteria. Indeed, ER is a gram negative bacterium that belongs to alpha proteobacteria and is an obligate intracellular pathogen that infects the endothelium of all blood vessels. ER has a complex life cycle described as chlamydia-like developmental cycle [16]. In the early stage of the cycle, elementary bodies, which represent the extracellular and infectious forms of the parasite, adhere to host target cells and then are engulfed. They remain within intracytoplasmic vacuoles, where they divided by binary fission to produce intermediate bodies and further reticulated bodies. After 4 to 6 days, the disruption of host cell leads to the release of numerous elementary bodies thus initiating a new infectious cycle. The genomic organization of this microorganism was revealed by the genome sequencing of two strains: Gardel and Welgevonden [17]. Even if comparative genomic studies provided data on the active mechanisms of genome plasticity [18,19], almost $30 \%$ of genes had unknown functions and genes involved in virulence, host cell penetration or invasion and intracellular growth processes remain unidentified.

Expression analysis of ER genes during life cycle, between attenuated and virulent strains, will allow the identification of the key factors involved in virulence mechanisms and the development of the bacteria. From the sequencing of Gardel and Welgevonden strains, whole genome ER microarrays were designed in order to validate sample quality obtained by SCOTS method and to evaluate the potential use of this method for further ER whole transcriptomic analysis. In vitro model using bovine endothelial cells and virulent Gardel strain allowed us to obtain a sufficient amount of ER RNA to perform such a study. 
In this article, we report for the first time the successful adaptation of the SCOTS method to an obligate intracellular bacterium, ER. We demonstrate the efficient isolation of specific bacterial transcripts from total RNA after 3 rounds of capture, with low amounts of $16 \mathrm{~S}$ ribosomal RNA contaminant. Moreover, besides the use of PCR amplifications, the differential gene expression was still detected by qRT-PCR and microarrays analysis. SCOTS method seems to be crucial for the analysis of gene expression especially at early stage of $E R$ development during the lag phase.

\section{Methods}

\section{Extraction of ER RNA from bovine infected cells}

The Gardel strain stock was isolated in 1982 in Guadeloupe from a goat infected experimentally with Amblyomma variegatum ticks collected from cows [20]. Gardel strain passage 39 and passage 47 were multiplied successively in bovine aorta endothelial (BAE) cells grown in Glasgow minimal essential medium complemented with fetal calf serum, tryptose-phosphate broth, and antibiotics [21] at $37^{\circ} \mathrm{C}, 5 \% \mathrm{CO} 2$, with a weekly passage on fresh cells [22]. BAE cells were infected with a calibrated inoculum of Gardel strain $\left(1.1 \times 10^{7}\right.$ elementary bodies per 1.42 $\times 10^{6}$ cells). Estimation of bacterial viability and quantity were both carried out by flow cytometry and fluorescent microscopy using live/dead BacLight Bacterial Viability Kit (Invitrogen, France) [23]. The infected cells were incubated at $37^{\circ} \mathrm{C}$ in a $5 \% \mathrm{CO}_{2}$ atmosphere. The supernatant was renewed only $24 \mathrm{~h}(6 \mathrm{ml})$ after infection and the cell monolayer was harvested by trypsinization every $24 \mathrm{~h}$ and centrifuged at $1700 \times \mathrm{g}$ for $5 \mathrm{~min}$ at $4{ }^{\circ} \mathrm{C}$. When $80 \%$ cell lysis was observed, after 120 hours post infection (hpi), supernatant and cellular debris were harvested and then ultra-centrifuged at $20,000 \times \mathrm{g}$ for $15 \mathrm{~min}$ at $4^{\circ} \mathrm{C}$ to collect elementary bodies. The pellets were placed in sterile eppendorfs and homogenized in $2.5 \mathrm{ml}$ of TRIzol reagent (Invitrogen). The cells lysed immediately and released RNA and DNA in the supernatant. The samples were immediately stored at $-80^{\circ} \mathrm{C}$ before RNA extraction.

\section{Extraction of total RNA with TRIzol}

For each time of collection after cell lysis (24 to $120 \mathrm{hpi}$ ), total RNA extraction procedure was carried out with TRIzol reagent (Invitrogen) according to the manufacturer's instructions. RNA pellets were dissolved in $100 \mu \mathrm{l}$ of DEPC water and treated with turboDNAse (Ambion, France) according to manufacturer's protocol in order to remove all contaminant DNA. The removal of bacterial genomic DNA (gDNA) contaminant in RNA samples was verified by PCR targeting $p C S 20$ gene using primers AB128 and AB129 which amplified specifically a $281 \mathrm{pb}$ of $E R$ as described previously [24] (table 1). The quantification of total RNA was performed by fluorimeter using ribogreen reagent (Invitrogen). The yield obtained after the extraction was between 3 to $25 \mu \mathrm{g}$. For each time of collection, total RNA samples were pooled in RNase free water at a final concentration of $0.5 \mu \mathrm{g} / \mu \mathrm{l}$.

\section{ER gDNA production and ER ribosomal DNA (rDNA) cloning for SCOTS method}

Genomic DNA ( $>50 \mu \mathrm{g}$ ) from Gardel strain passage 40 was extracted from elementary bodies, as previously described $[18,25]$. After high speed centrifugation $(20,000$ $\times \mathrm{g}$ during $30 \mathrm{~min}$ ), the pellet of elementary bodies was resuspended in $350 \mu \mathrm{l}$ of saline phosphate buffer. $150 \mu \mathrm{l}$ of DNase $(1 \mu \mathrm{g} / \mathrm{ml})$ was added to remove the contaminant bovine DNA from host cells and the samples were incubated at $37^{\circ} \mathrm{C}$ for $90 \mathrm{~min}$. The treatment was stopped by adding $25 \mathrm{mM}$ of EDTA. Whole bacterial DNA was obtained using QIAamp extraction kit (Qiagen, France) [26].

In $E R$, the organization of the $r r n$ operon coding the rRNAs is not canonical as the gene coding the 16S rRNA is $900 \mathrm{~kb}$ distant from the 23S-5S gene cluster [17]. Both rRNA $16 S$ and 23S - 5S cluster sequences were amplified using specific primers derived from $E R$ genome: rRNA 16SGarF- rRNA 16SGarR for 16S and rRNA5GarR; rRNA23SGarR for 5S-23S cluster (table 1). The PCR products were cloned into the high copy number vector PGEMT Easy (Promega, France). Competent Escherichia coli SURE2 cells were transformed with plasmid containing the inserts and isolated on LB-ampicillin-XGal (5-bromo4-chloro-3-indol- $\beta$-D-galactopyranoside)-IPTG (isopropyl- $\beta$-D-thiogalactopyranoside) selective medium. Positive clones were selected and the presence of the insert was checked using the specific primers previously cited. Transformants were grown in LB medium with appropriate antibiotic (Ampicillin $100 \mu \mathrm{g} / \mathrm{ml}$ ) and plasmid extraction was carried out with plasmid purification Maxi kit (Qiagen) according to manufacturer's protocol. Up to $300 \mu \mathrm{g}$ of plasmid pellets were homogenized in TE buffer $\mathrm{pH}$ 7.5. Both gDNA and rDNA were quantified by fluorometer using picogreen reagent (Invitrogen).

\section{Selective capture of transcribed sequences (SCOTS)}

For each time of the kinetic, $5 \mu \mathrm{g}$ of total RNA from Gardel strain passage 39 was reverse transcribed by random priming with Superscript II (Invitrogen) according to manufacturer's instructions. The reverse transcription was done using KpnI-RNA primers (table 1) containing a defined $5^{\prime}$ terminal sequence as a tag and a random nonamer at the $3^{\prime}$ end as in conditions previously described by [27] and [5]. Second-strand cDNA was synthesized by using Klenow fragment (Biolabs, France). Then, cDNA was amplified by PCR using the specific primers corresponding to the KpnI tag. This corresponded to cDNA before SCOTS (SCOTS $0 \times$ ). Reactions were prepared using the following PCR conditions: initial denaturation of $3 \mathrm{~min}$ at $94^{\circ} \mathrm{C}$ fol- 
Table I: Primers used for the detection of specific ER genes

\begin{tabular}{|c|c|c|c|c|}
\hline Primer name & Primer sequence & $\begin{array}{c}\text { Target gene or } \\
\text { sequence }\end{array}$ & $\begin{array}{l}\text { Product size } \\
\text { (bp) }\end{array}$ & $\begin{array}{c}\text { source } \\
\text { (references) }\end{array}$ \\
\hline$f f h-F 2^{a}$ & 5' GGTAGGTCTTCAAGGTGTTGGTAAA 3' & $F f h$ & 121 & this work \\
\hline$f f h-R 2$ & 5' AGTTTGAGCTGCAGGACGATATAA 3' & & & \\
\hline recA-FIa,b & 5' TTGAAAAAGCGTTTGGTCGTG 3' & recA & $|2|$ & this work \\
\hline recA-RI & 5' GGGAAACCACCAATACCCAAT 3' & & & \\
\hline$r p o D-F / a, b$ & 5' CAGAGGGTTGCAATTTCTTGATT 3' & $r p o D$ & 121 & this work \\
\hline rpoD-RI & 5' TCTGACCCACCATGTTGCAT 3' & & & \\
\hline I6S-Flab & 5' AGCGCAACCCTCATCCTTAG 3' & rRNA I6S & 121 & this work \\
\hline $\mid 6 S-R I$ & 5' AGCCCACCCTATAAGGGCC 3' & & & \\
\hline map / gardFa,b & 5' CACTTGAAGGAATGCCAGTTTCTC 3' & mapl & 85 & this work \\
\hline maplgardR & 5' CTTAGGATTTGTAGCATTGATTACTGACACT 3' & & & \\
\hline$A B / 28$ & 5' ACTAGTAGAAATTGCACAATCTAT 3' & pCS20 & 278 & Martinez et al., 2004 \\
\hline$A B / 29$ & 5' TGATAACTTGGTGCGGGAAATCCTT 3' & & & \\
\hline NKpnI-pdN9 & 5' GTGGTACCGCTCTCCGTCCGANNNNNNNNN 3' & Kpnl & I & Daigle et al., 200I \\
\hline NKpnl & 5' GTGGTACGGCTCTCCGTCCGA 3' & NKpnl tag & $200-400$ & \\
\hline ARN I 6SGarF & 5' AACTTGAGAGTTTGATCCTGGCT 3' & rRNA I6S & 1503 & this work \\
\hline ARNI6SGarR & 5' AGGAGGTAATCCAGCCGCAGGTT 3' & & & this work \\
\hline ARN5SGarR & 5' TCTCCCGTGCCTTAAGACAAA 3' & rRNA $23 S$ & 2935 & this work \\
\hline ARN23SGarF & 5' TTGATGGATGCCTTGGCGTTAA 3' & rRNA $5 S$ & & this work \\
\hline
\end{tabular}

a: pair of primers use for RT-PCR

b: pair of primers use for QRT-PCR

lowed by 25 cycles at $94^{\circ} \mathrm{C}$ for $45 \mathrm{~s}$, at $60^{\circ} \mathrm{C}$ for $45 \mathrm{~s}$, at $72^{\circ} \mathrm{C}$ for $60 \mathrm{~s}$ and a final extension of $10 \mathrm{~min}$ at $72^{\circ} \mathrm{C}$.

Selective capture of bacterial cDNA was done as previously described by [4] and [28]. ER gDNA (0.3 $\mu \mathrm{g})$ was photobiotinylated and then mixed with the rDNA 16S and $23 \mathrm{~S}+5 \mathrm{~S}(0.5 \mu \mathrm{g}$ of each plasmid pGEMT) in order to block the rRNAs region sites on the gDNA in TE buffer $\mathrm{pH}$ 9. The mixture was then sonicated and precipitated in ethanol $100 \%(2.5 \mathrm{v} / \mathrm{v}), \mathrm{NaOac} 3 \mathrm{M}(0.1 \mathrm{v} / \mathrm{v})$ and $1 \mu \mathrm{l}$ Glycogen $(1 \mu \mathrm{g} / \mathrm{ml})$. The gDNA-rDNA mixture and $5 \mu \mathrm{g}$ cDNA were denatured separately $3 \mathrm{~min}$ at $99^{\circ} \mathrm{C}$ in $4 \mu \mathrm{l}$ of hybridization buffer (10 mM EPPS [N-(2-hydroxyethyl) piperzine-N'-3-propanesulfonic acid]/1 mM EDTA) and prehybridized at $50^{\circ} \mathrm{C}$ for $30 \mathrm{~min}$. The temperature of hybridization was evaluated from the percentage of GC of ER genome (27\%). The prehybridization step allows the hybridization of ER rDNA to the gDNA, as it also allows the normalization of bacterial and eukaryotic cDNA by self-hybridization of highly present cDNA $[29,30]$. Immediately after adding $1 \mu \mathrm{l}$ of $\mathrm{NaCl} 1.5 \mathrm{M}$, the cDNA and bacterial gDNA pre-blocked with rDNA (gDNA-rDNA) were mixed and hybridized for $18 \mathrm{~h}$ at $50^{\circ} \mathrm{C}$ (hybridization step). Hybrids, representing ER cDNA fixed to ER gDNA, were captured with streptavidin-coated magnetic beads
(Dynal 280) according to the manufacturer's protocol. Selective cDNA was then eluted in $100 \mu \mathrm{l}$ of $\mathrm{NaOH} 0.4 \mathrm{~N}$, precipitated and amplified by NKpnI specific PCR as described. The PCR products were then visualized by ethidium bromide staining in 1.2\% agarose gels (Seakem) in $1 \times$ TAE buffer ( $40 \mathrm{mM}$ Tris- $\mathrm{HCl}, 6 \%$ acetic acid, $1 \mathrm{mM}$ EDTA, pH8) and purified with PCR purification kit (Qiagen). The initial amount of total RNA before SCOTS method for each time of infection was between 10 to 20 $\mu \mathrm{g}$ and was divided in 2 to 5 tubes with $0.5 \mu \mathrm{g} /$ tube. After this first round (SCOTS $1 \times$ ), the tubes corresponding to one condition were pooled and $10 \mu \mathrm{l}$ to $20 \mu \mathrm{l}$ of the pooled sample were precipitated depending on the intensity of purified cDNAs from the previous round. Two additional rounds of capture (SCOTS $2 \times$ and $3 \times$ ) were performed for each sample at each time point of infection $(24,48,72,96$ and $120 \mathrm{hpi})$ for further microarrays and qRT-PCR analyzes.

\section{Microarrays experiments}

a. ER Microarrays design

ER microarrays $(8 \times 15 \mathrm{k})$ used in this study were developed based on long oligo arrays generated by Agilent technology. These arrays contain 60-mer probes corresponding to 936 coding sequences (CDS) of Gardel 
strain and 909 sequences of Welgevonden strain, including the specific CDSs for each strain determined by the previous annotation of the two genomes [17]. The probes were designed using the following procedure: first, all 60mer probes were generated from CDS of Gardel and Welgevonden strains using standard thermodynamical constraints (TM $\in[78,83]$ and GC $\in[20,36]$ ) and a modified version of the OligoArray program [31]. For non specific CDSs, we chose the same probe for the same pair of orthologs between Gardel and Welgevonden strains. Then, we selected 1 or 2 of the most specific probes per gene by minimizing the number of matches to human and bovine mRNAs, extracted from the Ensembl database [32]. The microarrays contained a total of 1800 probes, with 5 replicates per probe, including 28 bovine genes as negative controls. Experimental data and associated microarray designs have been deposited in the NCBI Gene Expression Omnibus (GEO) http:// www.ncbi.nlm.nih.gov/geo/ under platforms GPL9697, GPL 9698 and serie GSE19208. Two different labeling procedures have been performed depending on whether the sample was treated or not following the SCOTS procedure.

\section{b. cDNA labeling}

Five hundred nanograms of total cDNA (from Gardel strain passage 39 at 24 and $96 \mathrm{hpi}$ ) from SCOTS procedure were randomly amplified and fluorescently labeled with the BioPrime array CGH Genomic labeling System kit (Invitrogen), by the incorporation of Cy3-dCTP (Amersham Biosciences) and then purified on a MinElute cleanup column (Qiagen). Before hybridization, quantification of Cy3-dCTP incorporation was performed by absorbance measurement at $550 \mathrm{~nm}$. The yield of cDNA labeling and the specific activity always exceeded to 1.65 $\mu \mathrm{g}$ and 9 pmol of Cy3 per cDNA, respectively, according to the manufacturer's recommendations.

\section{c. In vitro transcription (IVT)}

Total RNA was extracted as described above from Gardel strain samples passage 47, at 24 and 96 hpi. Eukaryotic ribosomal RNA was removed from the mixture by using the RiboMinus Transcriptome isolation kit (Invitrogen), according to the manufacturer's protocol. The amount and quality of purified RNA were monitored at various points throughout the purification process.

Three hundred nanograms of RiboMinus RNA fraction (Total RNA without eukaryotic rRNA) were then amplified and labeled using the Quick Amp Labeling kit of Agilent. The method consists of converting mRNA primed with a random primer containing a T7 promoter into double strand cDNA with MMLV-RT and then amplifying samples using a T7 RNA polymerase, which generates Cy3-labeled complementary (anti-sense) RNA (cRNA).

\section{d. Microarrays hybridization}

Cy3-labeled cRNAs and cDNAs obtained with both methods were used for hybridizations with Agilent Gene Expression Hybridization Kit (Agilent Technologies). Arrays were incubated at $65^{\circ} \mathrm{C}$ for $20 \mathrm{~h}$ in the hybridization chamber. After hybridization, arrays were washed according to the Agilent protocol. Genomic DNAs of ER Welgevonden and Gardel strains were labeled using BioPrime array CGH (Invitrogen) and then hybridized as positive control. cDNA samples (SCOTS $0 \times, 1 \times, 2 \times, 3 \times$ ) from Gardel strain passage 39 and samples generated by IVT from Gardel strain passage 47 at 24 hpi and $96 \mathrm{hpi}$ were hybridized on ER microarrays.

\section{e. Microarrays analysis}

Arrays were scanned and images were saved in TIFF format. The signal intensities of all spots on each image were quantified by Genepix pro 6.0 software (Molecular Devices Corporation, Downingtown, PA), and data were saved as ".txt" files for further analysis.

Data were log-transformed, mean-centered and reduced for an equal standard deviation between each slide using the GeneANOVA software [33]. The median value for each gene was calculated and correlation coefficients $\left(\mathrm{R}^{2}\right)$ between the several conditions were calculated. Genes were considered detected when their intensity of fluorescence was superior or equal to 3 fold the mean of background intensity.

\section{ER Southern blots}

Southern blots were carried out as described previously using the hybridization conditions explained by [34]. cDNAs produced at different times of infection (before SCOTS and after selective captures with $1 \times, 2 \times$ and $3 \times$ rounds of SCOTS) with rDNA16S and $23+5$ S were amplified by PCR digoxigenin (DIG)-labeling mix (Roche diagnostics, Meylan, France) according to manufacturer's instructions. Nylon membranes containing ER gDNA digested by HindIII were pre-hybridized at $50^{\circ} \mathrm{C}$ for $2 \mathrm{~h}$ in hybridization buffer [SSPE $6 \times(1 \times$ SSPE is $0.18 \mathrm{M} \mathrm{NaCl}$, $10 \mathrm{mM} \mathrm{NaH}_{2} \mathrm{PO}_{4}$, and $1 \mathrm{mM}$ EDTA $\left.\left.\{\mathrm{pH} 7.7\}\right)\right], 0.5 \%$ sodium dodecyl sulfate [SDS], 2\% (w/v) blocking reagent (Roche diagnostics). Probes were added to the hybridization buffer and incubated with the membranes for $16 \mathrm{~h}$ at $50^{\circ} \mathrm{C}$. Blots were then washed twice in buffer containing $2 \times$ SSPE, $0.1 \%$ SDS (w/v). Colorimetric detection was performed with anti-DIG antibody conjugated to alkaline phosphatase (Roche) and BCIP/NBT Buffered Substrate (Sigma Aldrich, France).

\section{Real-time quantitative RT-PCR targeting ribosomal I6S genes}

In order to evaluate the contaminant of ER rRNA16S transcripts in cDNA samples produced before and after SCOTS, qRT-PCR targeting ER 16S gene was performed on 
each sample of Gardel strain passage 39. Sybergreen fluorescent master mix reagent (Applied Biosystem) was used for qRT-PCR. Primers 16S-F1 and 16S-R1 used were described in table 1 and the size of the amplicon was 121 pb. qRT-PCR was performed systematically on cDNA before and after each round of SCOTS $(1 \times, 2 \times, 3 \times)$, using the following program: initial denaturation of $10 \mathrm{~min}$ at $95^{\circ} \mathrm{C}$, followed by 35 cycles of denaturation at $95^{\circ} \mathrm{C}$ for $30 \mathrm{~s}$, hybridization step at $60^{\circ} \mathrm{C}$ for $30 \mathrm{~s}$ and extension at $72^{\circ} \mathrm{C}$ for $60 \mathrm{~s}$. In order to quantify the number of copies per sample, a standard curve was established using gDNA of Gardel strain passage 27 serially diluted (from $2.9 \times 10^{5}$ copies to $2.9 \times 10^{1}$ ). Each sample was analyzed in duplicate.

\section{ER gene detection by RT-PCR and qRT-PCR in CDNA samples after selective capture}

The presence of 5 genes in cDNA samples and their enrichment by SCOTS method were evaluated using RTPCR and qRT-PCR amplifying small fragments of target genes $(\sim 120-300 \mathrm{pb})$ (table 1$)$ that are recA, ffh, rpoD, map1 and pCS20 [18]. map1 gene of ER encodes an outer membrane protein (major antigenic protein) $[35,36]$. ER specific gene pCS20 is highly conserved and used as target for molecular ER detection [24]. $r p o D$ gene encoding a polymerase sigma factor [37], ffh gene encoding a signal recognition particle protein and $r e c A$ gene (recombinase A) [38] are three housekeeping genes involved in $E R$ metabolism. The same primers and PCR conditions were used for RT and qRT-PCR.

For $E R$ gene detection by RT-PCR, cDNA samples were diluted in order to assess optimal cDNA concentrations and then to observe the gradual increase of cDNA detection after the different rounds of SCOTS (from $1 \times$ to $3 \times$ ). The dilution of cDNA samples depended on the time of infection: $10^{3}$ fold for $24 \mathrm{hpi}, 10^{4}$ fold for $72 \mathrm{hpi}, 10^{5}$ for 96 and $120 \mathrm{hpi}$. These dilutions were used for all the target genes except $p C S 20$. For $p C S 20$, samples were not diluted for $24 \mathrm{hpi}$, and diluted $10,10^{3}$ and $10^{2}$ fold for 72,96 and 120 hpi. RT-PCR was performed systematically on cDNA before and after each round of SCOTS $(1 \times, 2 \times, 3 \times)$ using the following program: initial denaturation of $3 \mathrm{~min}$ at $94^{\circ} \mathrm{C}$ followed by 40 cycles of denaturation at $94^{\circ} \mathrm{C}$ for $50 \mathrm{~s}$, hybridization step at $60^{\circ} \mathrm{C}$ for $50 \mathrm{~s}$ and extension at $72^{\circ} \mathrm{C}$ for $50 \mathrm{~s}$ and a final extension of $7 \mathrm{~min}$ at $72^{\circ} \mathrm{C}$. DNA of Gardel strain passage 18 was used as a positive control. PCR products were visualized by ethidium-bromidestained revelation in agarose gels. qRT-PCRs targeting map1, ffh and recA, were performed on the ABI Prism 7000 (Applied Biosystems) in a total reaction volume of $25 \mu \mathrm{l}$. This reaction contained $2 \mu \mathrm{l}$ of undiluted cDNA template (from the initial cDNA reverse transcribed $(0.5 \mu \mathrm{g} / \mu \mathrm{l})$ before capture and after SCOTS $3 \times$ ). In order to quantify the number of copies per sample, a standard curve was made with the gDNA of $E R$ (from $2.9 \times 10^{5}$ to $2.9 \times 10^{1}$ copies) as a template. Each sample was done in duplicate. A dissociation curve was produced in order to verify the presence of a single amplicon.

\section{Results}

\section{Enrichment of bacterial cDNA after SCOTS}

$E R$ CDNAs were produced after $1 \times, 2 \times$, and $3 \times$ SCOTS captures for each time point of infection. A PCR using KpnI primer was performed on cDNAs after each capture. Figure 1 shows amplicons obtained after KpnI PCR on Gardel strain passage 39, at $96 \mathrm{hpi}$ and $120 \mathrm{hpi}$. The signal detected after capture confirmed the efficiency of the selective capture by high affinity hybridization of cDNA to gDNA. Moreover, we showed a progressive diminution of the size of the amplified transcribed sequences following successive captures. Similar results were obtained for other post infection time points (data not shown). These results indicated that same capture phenomena were observed independently from the time of infection.

Southern blots were done on cDNAs before and after each capture for each time point of infection. Southern blots obtained using cDNA at $96 \mathrm{hpi}$ as probes on HindIIIdigested $E R$ gDNA are shown in figure 2. DIG-rDNA $23 S+5 S$ and $16 S$ were used to reveal the bands corresponding to ER rDNA (lane 1). Five distinct bands corresponding to rDNA were observed both before capture and after the first capture (figure 2). After successive capture, the results showed a significant increase of the colorimetric signal that traduces a larger recognition of $E R$ genes by DIG-cDNA at 96 hpi. These results demonstrated a progressive increase of bacterial cDNA complexity and amount following the successive rounds of captures. For other time points of infection, southern blots were done systematically and similar results were observed with a diminution of the ribosomal cDNA and an increase of the diversity of $E R$ transcripts after the third capture (data not shown).

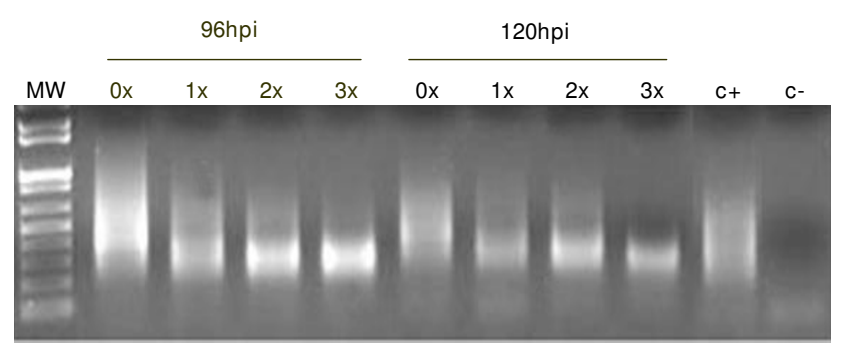

\section{Figure I}

NKpnI PCR amplicons of CDNAs of Gardel strain passage 39 after SCOTS. $0 x, 1 \times, 2 \times$ and $3 \times$ : cDNA amplicons of NKpnl PCR after 0, I, 2 or 3 rounds of capture. $\mathrm{C+}$ : positive control cDNA with NKpnl tag. C-: Negative control (Water). MW: Molecular weight 100 pb DNA ladder. hpi: hours post infection 


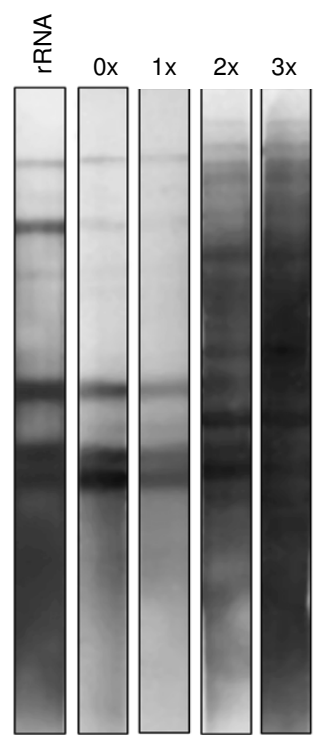

Figure 2

Southern blot using DIG labeling cDNAs of Gardel strain at 96 hpi. $0 \times, 1 \times, 2 \times$ and $3 \times$ : Southern blots showing cDNAs of Gardel strain passage 39 before and after one, two and three rounds of SCOTS. rRNA: Southern blot using DIG-rDNA 23S+5S and I6S.

The diminution of the amplicon sizes after KpnI PCR and results of Southern blot validates the enrichment of $E R$ cDNA and diminution of ribosomal cDNA and eukaryotic contaminant.

\section{Quantification of ribosomal RNA I6S contaminant after SCOTS by $q R T-P C R$}

The quantification of cDNA corresponding to $16 \mathrm{~S}$ cDNA contaminant was carried out before and after each round of SCOTS at the different time post infection by qRT-PCR (figure 3). Before capture, the amount of $16 \mathrm{~S}$ cDNA contaminant varied depending on time points post infection and on the amount of bacteria. At $24 \mathrm{hpi}$, there was a few $16 S$ cDNA contaminant ( 89 copies per sample). The range of contamination was between $4 \times 10^{3}$ to $18.2 \times 10^{3}$ copies for other time points post infection. We observed a decrease of $46 \%, 92 \%$ and $99 \%$ in ribosomal content after the third capture at 72, 96 and $120 \mathrm{hpi}$, with a final number of copies of $5.6 \times 10^{3}, 1.4 \times 10^{3}$ and 43 copies (figure 3 ). The main decrease was observed after the first capture. For $24 \mathrm{hpi}$, the initial number of $16 \mathrm{~S}$ cDNA copies was already low $(<90)$ and remained low after different captures.

\section{Detection of different ER transcribed sequences by RT- PCR and qRT-PCR before and after capture}

Amplicons corresponding to RT-PCR targeting map1, recA, $r p o D, f f h$ and $p C S 20$ at different time points and following successive captures were shown in table 2 . Before capture,

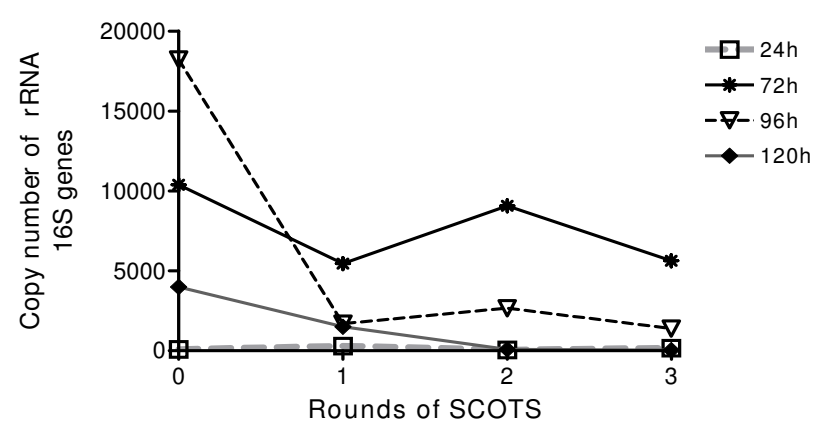

Figure 3

Quantitative RT-PCR targeting ER rRNA I 6S on cDNAs of Gardel strain after SCOTS at different time point post infection: $24,72,96$ and I 20 hours post infection.

the cDNAs of these genes were not detected. For map1 transcripts, one capture was sufficient to obtain a map1 amplicon at any time post infection. There was a significant and progressive increase of the amplification intensity after the second and third rounds, which demonstrated the enrichment of map1 transcripts (table 2 ). Depending on the gene and time point post infection considered, a positive signal was detected after the first (i.e. ffh at 24 hpi and recA, ffh at 72 hpi), second (i.e. recA, $f f h$ at $96 \mathrm{hpi}$ and $f f h$ at $120 \mathrm{hpi}$ ) or third capture (i.e. recA at $24 \mathrm{hpi}$ and $120 \mathrm{hpi}$ ). The increase of signal intensity was observed for all genes at any time point post infection after successive captures, except for pCS20 at 24 and 72 hpi. At 24 hpi, undiluted samples were used to detect pCS20 transcripts and there was no signal before capture. At $120 \mathrm{hpi}$, pCS20 amplification samples were diluted only at $10^{-2}$ to observe enrichment, compared to the $10^{-5}$ dilution used for the other genes. Globally, 3 rounds of capture were necessary to efficiently enrich the genes poorly expressed.

The qRT-PCR targeting map1, recA and $r p o D$ transcripts before and after 3 rounds of capture allowed to quantify the enrichment due to SCOTS method. Results expressed as the number of transcripts for each gene obtained by qRT-PCR are presented in figure 4 . Before capture, the number of transcripts was different depending on the target gene. For example, at 24 hpi there were $1.58 \times 10^{3}$ copies of map1 transcripts and only 70 and 10 copies of recA and $r p o D$. For all time points post infection, map1 was highly expressed compared to the 2 other genes (from 1 to $3 \log 10$ higher than recA and rpoD) (figure 4).

After 3 captures at $24 \mathrm{hpi}$, there was enrichment around 1000 fold of the amount of recA transcripts (from 70 to 66 $\times 10^{3}$ copies). For map1 transcripts, the number of copies increased from $1.58 \times 10^{3}$ to $1 \times 10^{8}$ copies after capture. Even when there was a single transcript per sample, for 
Table 2: Detection of ER specific genes by RT-PCR on total cDNA before and after SCOTS

\begin{tabular}{|c|c|c|c|c|c|c|c|c|c|c|c|c|c|c|c|c|}
\hline \multirow[t]{2}{*}{ Gene } & \multicolumn{4}{|c|}{24 hpi } & \multicolumn{4}{|c|}{72 hpi } & \multicolumn{4}{|c|}{96 hpi } & \multicolumn{4}{|c|}{ I 20 hpi } \\
\hline & $0 x$ & IX & $2 x$ & $3 x$ & $0 x$ & IX & $2 x$ & $3 x$ & $0 x$ & Ix & $2 x$ & $3 x$ & $0 x$ & $\mid x$ & $2 x$ & $3 x$ \\
\hline mapl & - & + & ++ & +++ & - & + & ++ & +++ & - & + & ++ & +++ & - & + & ++ & +++ \\
\hline recAl & - & - & - & + & - & + & ++ & +++ & - & - & ++ & +++ & - & - & - & +++ \\
\hline rpoD & - & - & + & ++ & - & + & ++ & +++ & - & - & ++ & +++ & - & - & - & +++ \\
\hline$f f h$ & - & + & ++ & +++ & - & + & ++ & +++ & - & - & ++ & +++ & - & - & ++ & +++ \\
\hline pCS20 & - & + & + & + & - & + & + & + & - & + & ++ & +++ & - & + & ++ & +++ \\
\hline
\end{tabular}

-: absence of amplicon after RT-PCR, +: Presence of amplicon after RT-PCR.

The number of $(+)$ corresponded to the intensity of amplification signal. $0 \times, 1 \times, 2 \times$ and $3 \times$ corresponded to results obtained on cDNA before and after one, two and three rounds of capture respectively. hpi: hours post infection

rpoD at 24 and $48 \mathrm{hpi}$ and $\operatorname{rec} A$ at $48 \mathrm{hpi}$, there was $11 \times$ $10^{3}, 14 \times 10^{3}$ copies and $15.4 \times 10^{3}$ copies after SCOTS. Before capture, there was an approximate 2 to $3 \log 10$ difference of expression between map1 and recA or $r p o D$, whereas an approximate $1 \log 10$ difference was measured after capture. The difference of expression between map1 and $r e c A$ or $r p o D$ was still observed after capture, whatever the culture time considered.

\section{A. Before SCOTS}

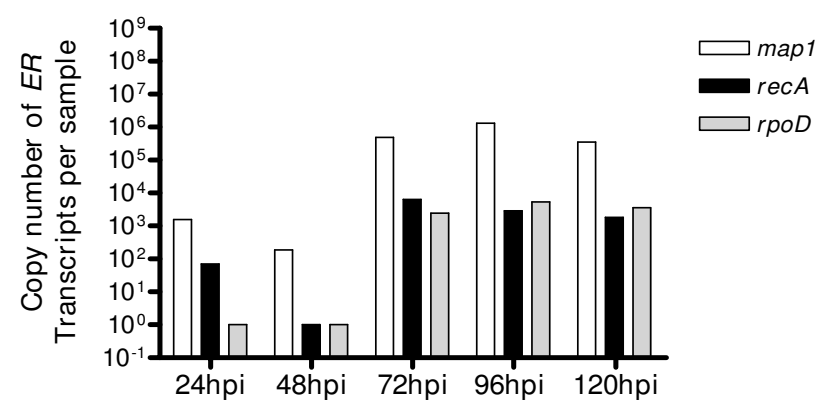

\section{B. After SCOTS}

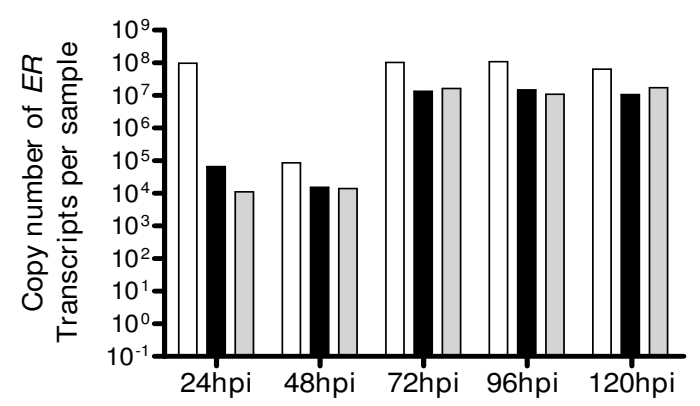

Figure 4

Quantitative RT-PCR of mapl, recA and rpoD genes on cDNA samples of Gardel strain before and after 3 rounds of capture. hpi: hours post infection.
Validation of selective captures using ER Microarrays

To validate ER selective captures, whole genome microarrays of $E R$ were used. Firstly, ER probes specificity was assessed by hybridizations with gDNA of Gardel and Welgevonden strains. Of the 1800 probes represented on our microarrays, 99.2 (1758/1772) and 99.1\% (1757/1772) of probes were detected for Gardel and Welgevonden strains gDNA respectively (figure 5a). There was no detection of bovine probes corresponding to contaminants. When comparing gDNA hybridizations obtained for 5 replicates per probe on two microarrays slides, there was a high correlation coefficient $\left(\mathrm{R}^{2}=0.97\right)$.

Using ER microarrays, two methods for generating ER transcripts probes were evaluated: direct IVT from "RiboMinus" RNA fraction and cDNA classical random priming for SCOTS samples (figure 5). The percentages of genes detected using samples generated by these methods are presented in figure $5 \mathrm{~b}$. Before any treatment (SCOTS $0 \times)$, only a small fraction of transcripts could be detected (from 0.05 to $10.4 \%$ ) for samples collected at 24 and 96 hpi. For early time post infection, there were only 19 genes (1\%) detected by microarrays using the IVT method on "RiboMinus" RNA fraction, whereas 3 rounds of SCOTS allowed the detection of $24 \%$ of transcripts (figure 5b). Even at $96 \mathrm{hpi}$, the percentage of transcripts detected was low using the IVT method. SCOTS method allowed the detection of 7 and 3.5 fold more gene transcripts compared to untreated and RiboMinus samples. Thus, these results confirmed the efficiency of SCOTS method for transcriptomic analysis.

To evaluate a potential bias of the SCOTS method for differential gene expression analysis, we calculated the coefficients of correlation between successive captures on Gardel strain cDNAs at 96 hpi (table 3). The coefficients of correlation between each round of capture were 0.84 , 0.98 and 0.98 respectively (table 3 ). The comparison of an untreated and a three SCOTS capture sample $\left(\mathrm{R}^{2}=0.7\right)$ indicated that SCOTS-mediated amplification was roughly linear. 
A
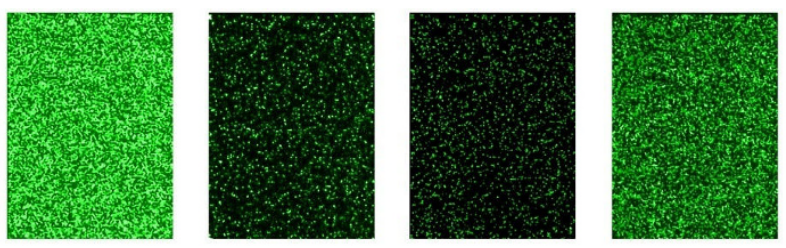

gDNA

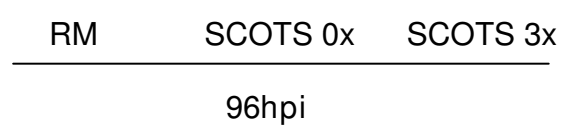

B
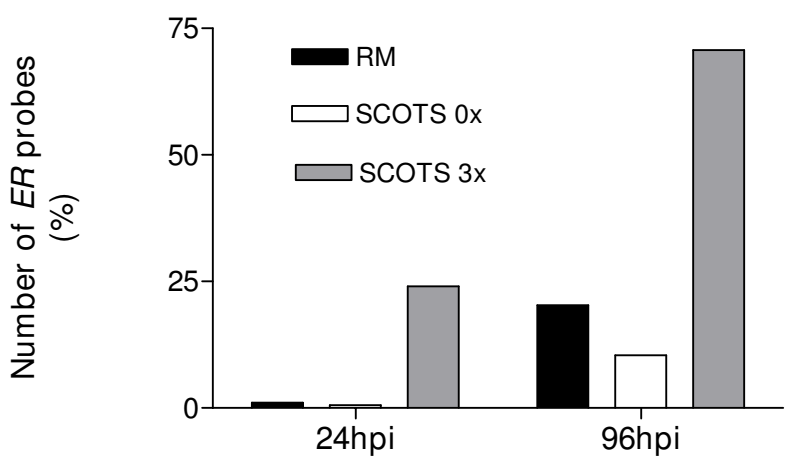

Figure 5

Detection of probes using Gardel strain cDNAs generated after Ribominus (RM) and SCOTS treatment. A: ER Microarray Hybridization with gDNA of Gardel strain passage 40 , with cRNAs from Gardel strain passage 47 using RiboMinus purification (RM), with cDNAs from Gardel strain passage 39 before SCOTS $(0 x)$ and after 3 rounds of capture (3x). B: Percentage of ER detected probes at 24 and $96 \mathrm{hpi}$ for cRNAs from Gardel strain passage 47 using RiboMinus purification (RM) with cDNAs from Gardel strain passage 39 before SCOTS $(0 x)$ and after 3 rounds of capture $(3 x)$.

\section{Discussion}

Obligate intracellular pathogens are a challenge for functional genomic studies to identify genes involved in bacterial pathogenesis, especially at different stages of development. Until now, only a few studies have been performed on whole Rickettsiales transcriptomes, thus providing a good illustration of this constraint [39]. Glo-

Table 3: Correlation coefficient $\left(R^{2}\right)$ for gene detection by $E R$ microarrays between the different rounds of SCOTS at $96 \mathrm{hpi}$

\begin{tabular}{ccccc}
\hline SCOTS & $\mathbf{0 \times / 1 \times}$ & $\mathbf{I} \times / 2 \times$ & $\mathbf{2 \times / 3 \times}$ & $\mathbf{0 \times / 3 \times}$ \\
\hline $\mathrm{R}^{2}$ & 0.84 & 0.98 & 0.98 & 0.7
\end{tabular}

bal proteomic expression studies were preferentially used in order to enhance our knowledge on pathogenesis of obligate intracellular pathogens, such as Ehrlichia, Rickettsia and Anaplasma [40-44]. Proteomic studies also avoided the inconvenience of working with ribosomal prokaryotic and host cell contaminants.

In our Rickettsiales model, we postulated that pathogenicity determinants should be differentially expressed in the virulent strains of $E R$ when compared to the same strain attenuated in vitro $[45,46]$. However, any future whole transcriptomic analysis of Rickettsiales bacteria will need to use efficient tools to eliminate both host cells contaminant and prokaryotic ribosomal transcripts.

A method of selection of prokaryotic transcripts, the RiboMinus method, based on the removal of eukaryotic ribosomal RNA, was tested for our model. No or few genes were detected on microarrays at any time post infection when using RiboMinus cRNA samples. The failure of the method could be due to the interference of important amount of eukaryotic transcripts. Another strategy, combining removal of eukaryotic contaminants with subsequent random amplification of prokaryotic cDNA, was used previously for Rickettsia conorii and gave convincing results for microarrays analysis $[39,47]$. However, SCOTS method for microarrays analysis uses small amounts of initial cDNA ( $3 \mu \mathrm{g}$ of total RNA) compared to this selective method (50 $\mu \mathrm{g}$ for MicrobENRICH) [47]. Thus, using SCOTS method, there was no limitation to produce biological samples and several different conditions (strains and time-points post infection) could be studied.

The innovative method of SCOTS, which has been used previously for non obligatory intracellular parasites [6], was adapted to our ER model to obtain adequate samples for further whole-genome transcripts profile analysis.

The size diminution of $E R$ cDNAs following successive captures illustrates a mechanism of generation of small cDNAs due to the nature of the Taq polymerase. Moreover, it shows the capture of smaller transcribed sequences (around 400 to $200 \mathrm{bp}$ ) after each successive round of SCOTS. This phenomenon was observed previously by Graham and Clark-Curtiss for Mycobacterium tuberculosis [4]. In their study, they showed that although there were potential biases in representing total mRNA of Mycobacterium due to SCOTS method (normalization and enrichment of cDNAs), the use of random priming to create cDNA provided a variety of different transcripts, thereby decreasing potential losses during amplification, normalization and enrichment. A progressive enrichment of $E R$ cDNA between the first and the third capture was observed by Southern blotting as observed with Mycobacterium tuberculosis [4]. 
Interference due to ribosomal contaminants in transcriptomic analysis was shown previously in a study comparing subtractive hybridization and SCOTS methods for Mycobacterium avium [48]. For initial samples, few signals were observed corresponding to rRNAs. After subtractive hybridization and SCOTS, an increased quantity of messenger RNAs was observed. The deficiency of detection before mRNA selection seemed to be due to the high amount of rRNAs. In our model, we also obtained a strong decrease of the quantity of ribosomal contaminant as demonstrated by Southern blots and qRT-PCR targeting $16 S$ gene. In an independent experiment, similar results were observed for attenuated Gardel strain by qRT-PCR (data not shown). Even if there was still detection of $16 \mathrm{~S}$ transcripts in samples after capture, the level of contamination was negligible compared to total ER CDNAs and should not hinder transcriptomic analysis.

The detection of all the 5 tested genes including bacterial housekeeping genes $r p o D$, ffh and $r e c A$ by RT-PCR or qRTPCR suggests that SCOTS method in $E R$ is efficient enough to enhance gene detection. Depending on the gene studied, variable numbers of captures were necessary to detect the specific transcript, illustrating the differential expression of genes in relation to life cycle. Three captures are required in order to detect poorly/lowest expressed genes and used for further transcriptomic analysis. Results of recA and rpoD qRT-PCR demonstrated that SCOTS method allowed the detection of transcripts accounted even when present as a single copy for early time-points post infection. Thus, our results demonstrated the efficiency of the SCOTS method for further expression analysis of an intracellular pathogen at early time-points post infection where the amount of eukaryotic contaminants was high. Beside this study, we report that map1 gene was strongly expressed as demonstrated both by RT-PCR and qRT-PCR. In parallel, we showed that pCS2O was the lowest expressed gene independently of the time of infection. For example, there was no detection of pCS20 transcripts after RT-PCR at early time post infection on undiluted samples.

As multiple PCRs were used for SCOTS method, one could suggest that all the transcripts would have the same level after selective capture. In this study, we demonstrated by both RT-PCR and qRT-PCR that the differential levels of expression were still observed after SCOTS. In a previous study, transcriptional analysis of $S$. enterica serovar Typhi within the macrophage revealed approximately 300 genes up-regulated at the defined point post infection compared to the supernatant [6].

In order to finalize the validation of SCOTS method for our model, we used ER microarrays. We first hybridized
Gardel and Welgevonden strains gDNA and observed that more than $99 \%$ of probes were detected. These microarrays offered an exciting opportunity to do the genomewide- analysis of $E R$ gene expression.

As previously shown by RT-PCR and qRT-PCR on a limited number of genes, our microarrays results with samples generated by SCOTS confirmed the efficiency of this method for our model. Thus, SCOTS method seems to be ideal for whole genome expression profiling of $E R$. This method is crucial for the study of early time-points post infection: $24 \%$ of ORFs could be detected whereas less than $1 \%$ was detected on untreated cDNA samples. For late time-points post infection, up to $70.7 \%$ of ORFs were detected after 3 rounds. Considering all the time points of infection, $80 \%$ of the annotated ORFs were detected in our model (data not shown), which is similar to what was previously observed with Salmonella Typhi within the macrophage [6]. Through the use of SCOTS, comparison of gene expression between $E R$ stages of development and between virulent and attenuated strains could be done on the overall CDS. This allows the targeting of genes involved in the invasion of host cells, in metabolism associated with bacterial growth (cell wall biogenesis, energy production, translation, traduction) and in pathogenesis sensu stricto.

Moreover, microarrays results demonstrated for overall $E R$ genes that there was a good correlation between expression of genes comparing any round of SCOTS at 96 hpi. The lowest coefficient of correlation $\left(\mathrm{R}^{2}=0.7\right)$ was between SCOTS $0 \times$ and $3 \times$ samples. This was mainly due to the absence of detection of several genes before capture which could be detected after 3 rounds: the percentage of genes detected increased from 10.4 (SCOTS 0) to 70.7\% (SCOTS 3). For genes already detected before capture, their level of expression was saturated after capture diminishing the correlation between SCOTS $0 \times$ and $3 \times$. For attenuated Gardel, SCOTS $0 \times$ and $3 \times$ samples $(96 \mathrm{hpi}$ ) were hybridized on $E R$ microarrays and a higher correlation coefficient $\left(\mathrm{R}^{2}=0.87\right)$ was observed (data not shown). This preliminary result on attenuated Gardel strain, confirmed the limited bias due to SCOTS method on the gene expressions. Our microarrays data supported results obtained by qRT-PCR on map1, recA and $r p o D$ (at any time-point post infection). The differential of gene expression diminished but was still detected before and after capture. However, for further transcriptomic analysis, we will focus on genes strongly differentially expressed or presence/absence of genes in order to target genes mainly involved in pathogenesis $[39,49]$. In our model, difference of gene expression will be assessed by hybridization of SCOTS CDNA on total ER microarrays and then validated by qRT-PCR on untreated cDNA. 


\section{Conclusions}

Our study reported herein demonstrated that SCOTS method has proven to be suitable for microarray-based transcriptome analysis of $E R$ and as such can be potentially applicable to other obligate intracellular bacteria. SCOTS method avoids interferences due to host cells and prokaryotic ribosomal contaminants. Moreover, it allows the enhancement of specific transcripts and induced a limited bias in their relative amount. Thus, SCOTS method will offer the opportunity to study molecular mechanisms that take place in early stages of $E R$ infection and to identify genes involved in the pathogenesis of this obligate intracellular bacterium.

\section{Authors' contributions}

Conceived and designed the experiments: LE, FD, DFM, BM, RF, AV, PB, DM, TL, NV. Performed the experiments: LE, VP, CS, VM, NV. Analyzed the data: LE, DFM, BM, NV. Contributed reagents/materials/analysis tools: LE, FD, BM, AV. Wrote the paper: LE, FD, DFM, TL, NV. All authors read and approved the final manuscript.

\section{Acknowledgements}

This work was supported by EPIGENEVAC project under contract number [INCO-CT-2005-0037/3] financed by the European Union, by "Institut National en Recherche Agronomique" and "Centre de Coopération International en Recherche Agronomique pour le Développement" financial fund and by Franco-Canadian fund: "Fonds France-Canada pour la Recherche".

We thank Dr Rupert Pegram for his helpful comments.

\section{References}

I. Belland RJ, Zhong G, Crane DD, Hogan D, Sturdevant D, Sharma J, Beatty WL, Caldwell HD: Genomic transcriptional profiling of the developmental cycle of Chlamydia trachomatis. Proc Natl Acad Sci USA 2003, I00(14):8478-8483.

2. Hinton JC, Hautefort I, Eriksson S, Thompson A, Rhen M: Benefits and pitfalls of using microarrays to monitor bacterial gene expression during infection. Curr Opin Microbiol 2004, 7(3):277-282.

3. Alland D, Kramnik I, Weisbrod TR, Otsubo L, Cerny R, Miller LP, Jacobs WR Jr, Bloom BR: Identification of differentially expressed mRNA in prokaryotic organisms by customized amplification libraries (DECAL): the effect of isoniazid on gene expression in Mycobacterium tuberculosis. Proc Natl Acad Sci USA 1998, 95(22): 13227-13232.

4. Graham JE, Clark-Curtiss JE: Identification of Mycobacterium tuberculosis RNAs synthesized in response to phagocytosis by human macrophages by selective capture of transcribed sequences (SCOTS). Proc Natl Acad Sci USA 1999, 96(20): II554-1 I 559 .

5. Daigle F, Graham JE, Curtiss R: Identification of Salmonella typhi genes expressed within macrophages by selective capture of transcribed sequences (SCOTS). Mol Microbiol 200I, $4 I(5):|2| I-\mid 222$.

6. Faucher SP, Porwollik S, Dozois CM, McClelland M, Daigle F: Transcriptome of Salmonella enterica serovar Typhi within macrophages revealed through the selective capture of transcribed sequences. Proc Natl Acad Sci USA 2006, 103(6): $1906-19 \mid 1$.

7. Baltes N, Buettner FF, Gerlach GF: Selective capture of transcribed sequences (SCOTS) of Actinobacillus pleuropneumoniae in the chronic stage of disease reveals an HlyX- regulated autotransporter protein. Vet Microbiol 2007, I 23(I3): $|10-12|$.

8. Baltes N, Gerlach GF: Identification of genes transcribed by Actinobacillus pleuropneumoniae in necrotic porcine lung tissue by using selective capture of transcribed sequences. Infect Immun 2004, 72(I I):67। I-67I 6.

9. Provost A, Bezuidenhout JD: The historical background and global importance of heartwater. Onderstepoort J Vet Res 1987, 54(3): $165-169$.

10. Barré N, Uilenberg G, Morel PC, Camus E: Danger of introducing heartwater onto the American mainland: potential role of indigenous and exotic Amblyomma ticks. Onderstepoort J Vet Res 1987, 54(3):405-4I7.

II. Uilenberg G: Experimental transmission of Cowdria ruminantium by the Gulf coast tick Amblyomma maculatum: danger of introducing heartwater and benign African theileriasis onto the American mainland. Am J Vet Res 1982, 43(7): 1279-1282.

12. Jongejan F, Wassink LA: Lack of cross-protection between Cowdria ruminantium and Ehrlichia phagocytophila. Rev Elev Med Vet Pays Trop I99I, 44(4):425-428.

13. Mahan SM, Allsopp B, Kocan KM, Palmer GH, Jongejan F: Vaccine strategies for Cowdria ruminantium infections and their application to other ehrlichial infections. Parasitol Today 1999, I5(7):290-294.

14. Reddy GR, Sulsona CR, Harrison RH, Mahan SM, Burridge MJ, Barbet AF: Sequence heterogeneity of the major antigenic protein I genes from Cowdria ruminantium isolates from different geographical areas. Clin Diagn Lab Immunol 1996, 3(4):417-422.

15. Zweygarth E, Josemans AI, Van Strijp MF, Lopez-Rebollar L, Van Kleef M, Allsopp BA: An attenuated Ehrlichia ruminantium (Welgevonden stock) vaccine protects small ruminants against virulent heartwater challenge. Vaccine 2005, 23(14): 1695-I 702.

16. Jongejan $F$, Zandbergen TA, Wiel PA van de, de Groot M, Uilenberg G: The tick-borne rickettsia Cowdria ruminantium has a Chlamydia-like developmental cycle. Onderstepoort J Vet Res I99|, 58(4):227-237.

17. Frutos R, Viari A, Ferraz C, Bensaid A, Morgat A, Boyer F, Coissac E, Vachiery N, Demaille J, Martinez D: Comparative genomics of three strains of Ehrlichia ruminantium: a review. Ann N Y Acad Sci 2006, 1081:417-433.

18. Frutos R, Viari A, Ferraz $C$, Morgat A, Eychenie $S$, Kandassamy $Y$, Chantal I, Bensaid A, Coissac E, Vachiery N, Demaille J, Martinez D: Comparative genomic analysis of three strains of Ehrlichia ruminantium reveals an active process of genome size plasticity. J Bacteriol 2006, I 88(7):2533-2542.

19. Frutos R, Viari A, Vachiery N, Boyer F, Martinez D: Ehrlichia ruminantium: genomic and evolutionary features. Trends Parasitol 2007, 23(9):414-419.

20. Uilenberg G, Camus E, Barre N: [A strain of Cowdria ruminantium isolated in Guadeloupe (French West Indies)]. Rev Elev Med Vet Pays Trop 1985, 38(I):34-42.

21. Bezuidenhout JD, Paterson CL, Barnard BJ: In vitro cultivation of Cowdria ruminantium. Onderstepoort J Vet Res 1985, 52(2): I I3-120.

22. Martinez D, Swinkels J, Camus E, Jongejan F: [Comparison between 3 antigens for the serodiagnosis of heartwater disease by indirect immunofluorescence]. Rev Elev Med Vet Pays Trop 1990, 43(2): 159-166.

23. Vachiery N, Lefrancois T, Esteves I, Molia S, Sheikboudou C, Kandassamy $Y$, Martinez $D$ : Optimisation of the inactivated vaccine dose against heartwater and in vitro quantification of Ehrlichia ruminantium challenge material. Vaccine 2006, 24(22):4747-4756.

24. Martinez D, Vachiery N, Stachurski F, Kandassamy Y, Raliniaina M, Aprelon R, Gueye A: Nested PCR for detection and genotyping of Ehrlichia ruminantium: use in genetic diversity analysis. Ann N Y Acad Sci 2004, 1026: 106-I I 3.

25. Martinez D, Maillard JC, Coisne S, Sheikboudou C, Bensaid A: Protection of goats against heartwater acquired by immunisation with inactivated elementary bodies of Cowdria ruminantium. Vet Immunol Immunopathol I994, 4 I (I-2): I53-I63.

26. Perez JM, Martinez D, Debus A, Sheikboudou C, Bensaid A: Development of an in vitro cloning method for Cowdria ruminantium. Clin Diagn Lab Immunol I997, 4(5):620-623. 
27. Froussard P: A random-PCR method (rPCR) to construct whole cDNA library from low amounts of RNA. Nucleic Acids Res 1992, 20( I I):2900.

28. Daigle F, Hou JY, Clark-Curtiss JE: Microbial gene expression elucidated by selective capture of transcribed sequences (SCOTS). Methods Enzymol 2002, 358:108-122.

29. Hahn WE, Pettijohn DE, Van Ness J: One strand equivalent of the Escherichia coli genome is transcribed: complexity and abundance classes of mRNA. Science 1977, I97(4303):582-585.

30. Ko MS, Ko SB, Takahashi N, Nishiguchi K, Abe K: Unbiased amplification of a highly complex mixture of DNA fragments by 'Ione linker'-tagged PCR. Nucleic Acids Res 1990 , I 8( 1 4):4293-4294.

31. Rouillard JM, Zuker M, Gulari E: OligoArray 2.0: design of oligonucleotide probes for DNA microarrays using a thermodynamic approach. Nucleic Acids Res 2003, 3 I (I 2):3057-3062.

32. Hubbard TJ, Aken BL, Ayling S, Ballester B, Beal K, Bragin E, Brent S, Chen Y, Clapham P, Clarke L, Coates G, Fairley S, Fitzgerald S, Fernandez-Banet J, Gordon L, Graf S, Haider S, Hammond M, Holland R, Howe K, Jenkinson A, Johnson N, Kahari A, Keefe D, Keenan S, Kinsella R, Kokocinski F, Kulesha E, Lawson D, Longden I, Megy K, Meidl P, Overduin B, Parker A, Pritchard B, Rios D, Schuster M, Slater G, Smedley D, Spooner W, Spudich G, Trevanion S, Vilella A, Vogel J, White S, Wilder S, Zadissa A, Birney E, Cunningham F, Curwen V, Durbin R, Fernandez-Suarez XM, Herrero J, Kasprzyk A, Proctor G, Smith J, Searle S, Flicek P: Ensembl 2009. Nucleic Acids Res 2009:D690-697.

33. Didier G, Brezellec P, Remy E, Henaut A: GeneANOVA--gene expression analysis of variance. Bioinformatics 2002, I 8(3):490-49|.

34. Bekker CP, Postigo M, Taoufik A, Bell-Sakyi L, Ferraz C, Martinez D, Jongejan F: Transcription analysis of the major antigenic protein I multigene family of three in vitro-cultured Ehrlichia ruminantium isolates. I Bacteriol 2005, I 87( | 4):4782-479 I.

35. Allsopp MT, Dorfling CM, Maillard JC, Bensaid A, Haydon DT, van Heerden $\mathrm{H}$, Allsopp BA: Ehrlichia ruminantium major antigenic protein gene (mapl) variants are not geographically constrained and show no evidence of having evolved under positive selection pressure. J Clin Microbiol 200 I, 39( I I):4200-4203.

36. van Vliet $A H$, Jongejan $F$, van Kleef $M$, Zeijst BA van der: Molecular cloning, sequence analysis, and expression of the gene encoding the immunodominant 32-kilodalton protein of Cowdria ruminantium. Infect Immun |994, 62(4): | 45 |- | 456.

37. Savli H, Karadenizli A, Kolayli F, Gundes S, Ozbek U, Vahaboglu H: Expression stability of six housekeeping genes: A proposal for resistance gene quantification studies of Pseudomonas aeruginosa by real-time quantitative RT-PCR. J Med Microbiol 2003, 52(Pt 5):403-408.

38. Takle GW, Toth IK, Brurberg MB: Evaluation of reference genes for real-time RT-PCR expression studies in the plant pathogen Pectobacterium atrosepticum. BMC Plant Biol 2007, 7:50.

39. Renesto P, Rovery C, Schrenzel J, Leroy Q, Huyghe A, Li W, Lepidi $H$, Francois $P$, Raoult $D$ : Rickettsia conorii transcriptional response within inoculation eschar. PLOS ONE 2008, 3(II):e368I.

40. Ge Y, Rikihisa $Y$ : Identification of novel surface proteins of Anaplasma phagocytophilum by affinity purification and proteomics. J Bacteriol 2007, I89(2I):7819-7828.

4l. Wang X, Kikuchi T, Rikihisa Y: Proteomic identification of a novel Anaplasma phagocytophilum DNA binding protein that regulates a putative transcription factor. J Bacteriol 2007 , I 89(1 3):4880-4886

42. Ogawa M, Renesto P, Azza S, Moinier D, Fourquet P, Gorvel JP, Raoult D: Proteome analysis of Rickettsia felis highlights the expression profile of intracellular bacteria. Proteomics 2007, 7(8): $1232-1248$

43. Renesto P, Azza S, Dolla A, Fourquet P, Vestris G, Gorvel JP, Raoult $D$ : Proteome analysis of Rickettsia conorii by two-dimensional gel electrophoresis coupled with mass spectrometry. FEMS Microbiol Lett 2005, 245(2):23 I-238.

44. Huang $H$, Lin $M$, Wang $X$, Kikuchi T, Mottaz $H$, Norbeck A, Rikihisa $Y$ : Proteomic analysis of and immune responses to Ehrlichia chaffeensis lipoproteins. Infect Immun 2008, 76(8):3405-34I4.

45. Jongejan F: Protective immunity to heartwater (Cowdria ruminantium infection) is acquired after vaccination with in vitro-attenuated rickettsiae. Infect Immun I99I, 59(2):729-73 I.
46. Martinez D: Analysis of the immune response of ruminants to Cowdria ruminantium infection. Utrecht: Utrecht University; 1997.

47. La MV, Francois P, Rovery C, Robineau S, Barbry P, Schrenzel J, Raoult $D$, Renesto $P$ : Development of a method for recovering rickettsial RNA from infected cells to analyze gene expression profiling of obligate intracellular bacteria. J Microbiol Methods 2007, 7 I (3):292-297.

48. Hou JY, Graham JE, Clark-Curtiss JE: Mycobacterium avium genes expressed during growth in human macrophages detected by selective capture of transcribed sequences (SCOTS). Infect Immun 2002, 70(7):37|4-3726.

49. Faucher SP, Curtiss R, Daigle F: Selective capture of Salmonella enterica serovar typhi genes expressed in macrophages that are absent from the Salmonella enterica serovar Typhimurium genome. Infect Immun 2005, 73(8):52I 7-522I.
Publish with Bio Med Central and every scientist can read your work free of charge

"BioMed Central will be the most significant development for disseminating the results of biomedical research in our lifetime. "

Sir Paul Nurse, Cancer Research UK

Your research papers will be:

- available free of charge to the entire biomedical community

- peer reviewed and published immediately upon acceptance

- cited in PubMed and archived on PubMed Central

- yours - you keep the copyright 